\title{
Fluorination of Aryl Trifluoroborates
}

\section{Key words}

fluorination

palladium

arylboron reagents

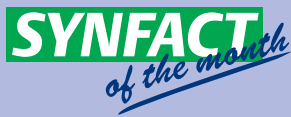

$\mathrm{R}=$ (substituted) aliphatic residues, ketones, amides, carboxylic acids, esters, alcohols, bromides terpy $=2,2^{\prime}: 6^{\prime}, 2^{\prime \prime}$-terpyridine
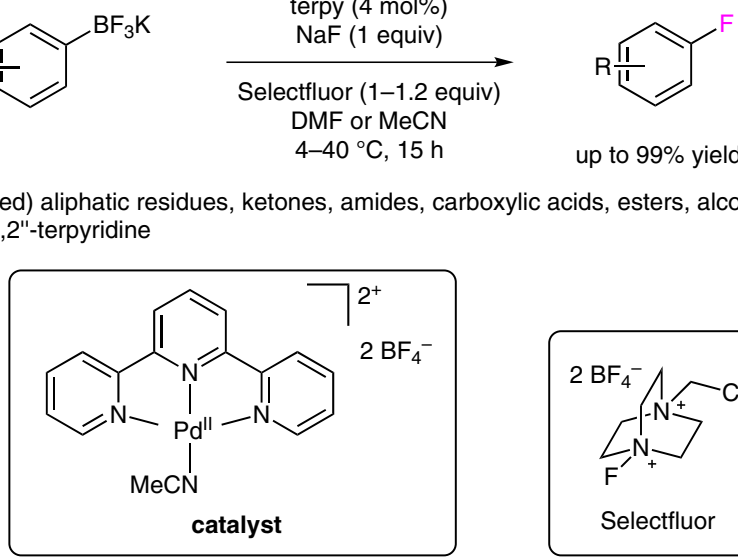

up to $99 \%$ yield
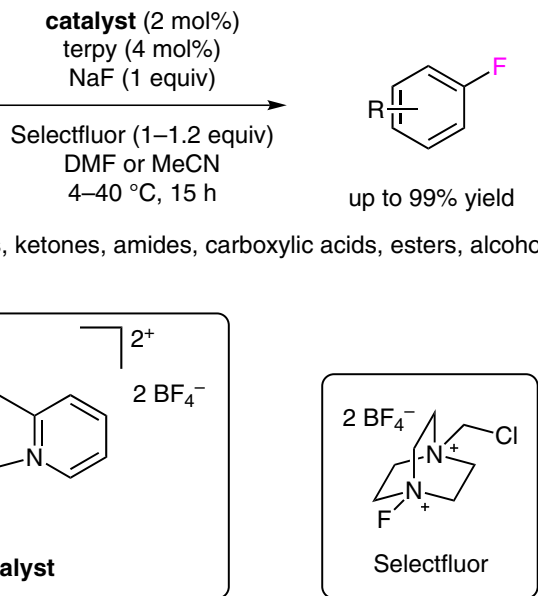

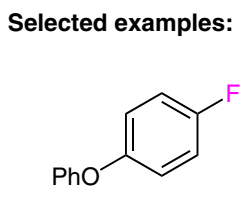

$99 \%$ yield<smiles>NC(=O)c1ccc(F)cc1</smiles><smiles>CCOC(=O)/C(C#N)=C/c1ccc(F)cc1</smiles>

$96 \%$ yield<smiles></smiles><smiles>OCCCc1ccc(F)cc1</smiles>

$71 \%$ yield<smiles>CC(C)(C)OC(=O)Oc1cc(F)c(CCN2C(=O)CCC2=O)cc1OC(C)(C)C</smiles>

$74 \%$ yield<smiles>O=C(O)Cc1ccc(F)cc1</smiles>

$74 \%$ yield<smiles>O=c1ccoc2ccc(F)cc12</smiles>

$83 \%$ yield
Significance: An air- and moisture-stable terpyridyl-palladium(II) precatalyst is found to be very active in the catalytic fluorination of aryl trifluoroborates. This palladium-catalyzed fluorination reaction is also applicable to other common arylboronic acids such as pinacol boronic esters, boronic acids, or MIDA esters via in situ formation of the respective aryl trifluoroborates with $\mathrm{NaF}$ and $\mathrm{KH}_{2} \mathrm{~F}$.
Comment: The authors propose a single electron transfer (SET) mechanism involving a palladium(III) intermediate. First, oxidation of the palladium(II) precatalyst by Selectfluor affords a palladium(III) intermediate and a Selectfluor radical cation. $F^{\bullet}$ transfer from the Selectfluor radical cation to the aryl trifluoroborate forms the C-F bond and a delocalized radical. SET from the radical to the palladium(III) intermediate generates the starting palladium(II) species and releases the aryl fluoride product as well as $\mathrm{BF}_{3}$. 